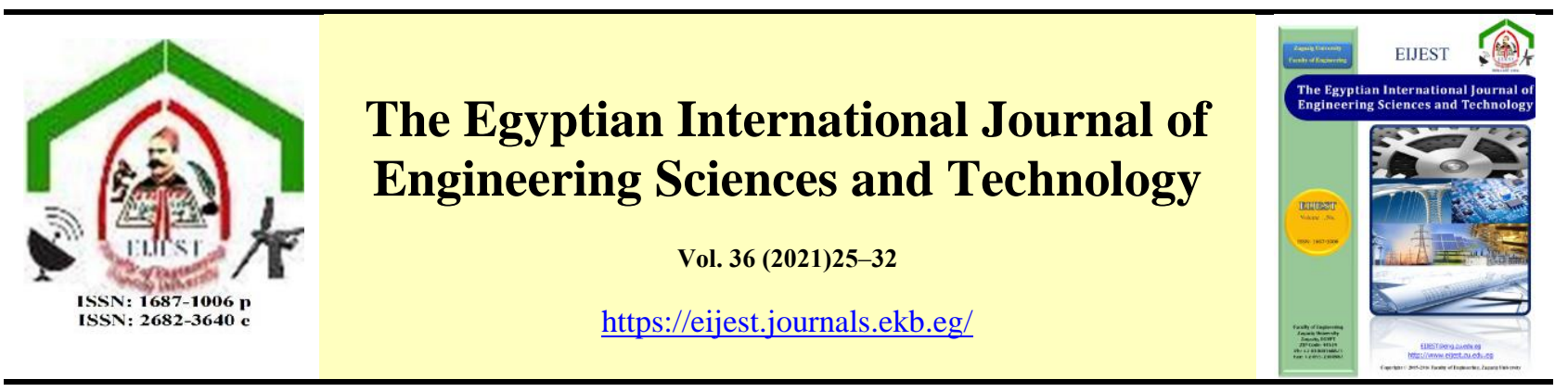

\title{
Strengthening of Coupled Shear Walls - An overview
}

\author{
Amany Abdel-Rahim ${ }^{a *}$, Mohamed Emara ${ }^{b}$, Hilal Hassanc, Suzan A. A. Mustafa ${ }^{c}$ \\ ${ }^{a}$ MSc student Structural Engineering, Faculty of Engineering, Zagazig University, Zagazig, Egypt. \\ b Assistant Professor Structural Engineering. Dept., Faculty of Engineering, Zagazig University, Zagazig, Egypt. \\ ${ }^{\mathrm{c}}$ Associate professor Structural Eng. Dept., Faculty of Eng., Zagazig University, Zagazig, Egypt.
}

\begin{tabular}{l}
\hline A R T I C L E I N F O \\
\hline Keywords: \\
Coupling beams \\
Coupled shear walls \\
Conventionally reinforced \\
Strengthening \\
Fibre Reinforced Polymers \\
Improve \\
Energy absorption capacity
\end{tabular}

Notations:

FRP

\begin{abstract}
A B S T R A C T
Coupling beams are considered one of the most important structural elements due to their vital role in resisting lateral loads by improving the overall building stiffness and reducing the impact of the overturning. The resistance of coupled shear walls (CSWs) to earthquakes depends on the coupling beam (CB) for enhancing the ductility of the system and improving the energy absorption capacity. There are two main types of coupling beams; diagonally reinforced coupling beams and conventionally reinforced ones. In the case of diagonal reinforcement, which is being currently recommended by the new design codes, the coupling beams are more efficient in consolidating the walls and providing better performance in resisting earthquakes. On the other hand, the diagonal reinforcing configuration showed some difficulties in terms of construction. There are already existing buildings that have conventionally reinforced coupling beams, which were designed according to the old codes. These coupling beams are in extreme need of strengthening to resist earthquakes. Therefore, some studies have been conducted to find an alternative to the diagonal reinforcing scheme of coupled shear walls. The methods of strengthening differed whether using steel plates or fibrereinforced polymers sheets. Nowadays Fibre Reinforced Polymers (FRP) are being widely used to strengthen coupling beams and improve the structural behavior of coupled shear walls. This paper presents a summary of some studies available in the literature concerning the strengthening of the coupling beams and coupled shear walls using FRP. Strengthening method, strengthening configurations, failure modes, and test setups are summarized.
\end{abstract}

\section{Introduction}

Shear walls and coupled shear walls are highly efficient structural elements to resist lateral loads and earthquakes, especially in tall buildings, as they are more stiff and strong than other systems and contribute significantly in energy absorption, so they work on the stability of the structure when exposed to these loads [1]. As a result of the architectural requirements and taking into account the service requirements of the structure, openings are made through the walls. For this purpose, these walls are connected to each other with ductile links called coupling beams that work to transmit forces through wall piers. Coupling beams (CBs) are also considered an important structural element in seismic design through reducing the coupled shear wall's bending moment at the base [1]. Despite their small dimensions and stiffness, coupling beams (CBs), combined with shear walls, can provide better resistance to lateral loads especially earthquakes

\footnotetext{
* Corresponding author. Tel.: +2-01273846856.
}

Email address: amanyabdelrahim5@gmail.com. 
compared to other systems as they exhibit better ductility and energy dissipation. Coupling beam can carry moment and shear forces making the two shear walls work together. Coupling beams can be divided into two types according to their reinforcing schemes; conventionally reinforced coupling beams, which have span to depth ratio ((L/D) $\geq 2)$ and diagonally reinforced beams with $((\mathrm{L} / \mathrm{D})<2)$ [2]. According to ACI building code 318-08 [3], the coupling beam sections in seismically high areas should include the use of diagonal reinforcement in the design to resist the internal shear requirement to ensure ideal seismic performance, despite that, there is a difficulty in implementing this type of reinforcement during construction in addition to its high cost. Moreover, it has been found that some buildings containing conventionally reinforced $\mathrm{CBs}$ need to be strengthened to increase their resistance to earthquakes [4]. The coupled shear wall's stiffness is much higher than the stiffnesses of separate wall piers, so the coupled shear wall's (CSWs) behavior is governed by the rigidity of the coupling beams as presented in Fig. 1. The coupled shear wall's structural (CSWs) behavior is measured by the degree of coupling (DC). It is defined as the ratio of the push-pull couple resisting overturning moment in the walls to the total structural overturning moment, as follows [4]:

$$
D C=\frac{P L c g}{P L c g+M_{1}+M_{2}}
$$

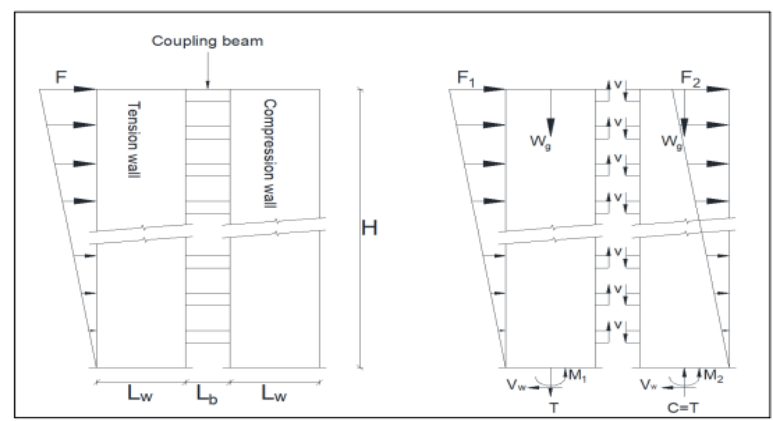

Fig. 1. Forces in coupled shear walls [4].

where $\mathrm{P}$ is the force resulting from the coupling process, whether it is tension or compression; $\mathrm{L}_{\mathrm{cg}}$ is the arm of torque between the centroids of the wall pier and $M_{1}, M_{2}$ are the resistive moment by each wall pier. The wall system acts as a single shear wall and no frame action would be observed as a result of increasing the stiffness of coupling beam and the degree of coupling approaches unity. In contrast, if the coupled shear walls behave as separate wall piers, this will occur as a result of the extremely flexible coupling beams. Therefore, for different degrees of coupling, various seismic force reduction factors; (R) were designated in NBCC 2015 [5]. In partially coupled shear walls $\mathrm{R}$-value equal to 3.5 are considered for Buildings with a DC less than $66 \%$. Structures with a DC greater than $66 \%$ are classified as fully coupled shear walls with R-value of 4.0 [4]. There are few studies that investigated the strengthening of coupling beams with FRP sheets and there are almost no studies on reinforcing coupling beams with FRP bars. Experimental investigation on the strengthening of coupled shear walls has been conducted by many researchers. It was concluded that the strengthening with steel plates is proved to be efficient in improving the coupled shear walls seismic behavior, but the separation of the plates was one of the obvious defects of this system. As for the strengthening with carbon fiber reinforced polymers laminates, the use of diagonal laminates has been proven as an alternative to diagonal reinforcement, but more types of FRP material such as basalt and other schemes of strengthening must be studied.

\section{Modes of failure of coupled shear walls}

Different failure modes of CSWs may occur according to the stiffness and strength of coupling beams. When the plastic hinges are formed at the end of the coupling beam before the walls, this means that the coupling beam yield before the wall, which indicates that the system has adequate ductility. When plastic hinges appeared on the bottom of the walls only, the beams may not yield for its high flexural capacity and stiffness [6]. The coupled shear walls behave as a separate wall when the shear failure is exhibited in the coupling beams first [4]. From here, the failure modes of coupled shear walls structures can be classified into three basic modes of failure. They depend on the behavior of the coupling beam and the degree of interaction, as follows:

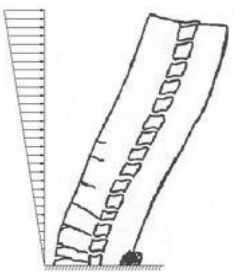

(a)

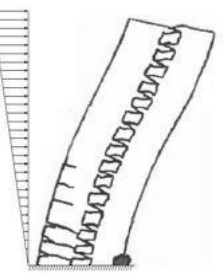

(b)

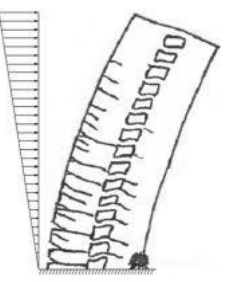

(c)
Fig. 2. Different failure modes of coupled shear walls, (a) Flexural failure mode, (b) Shear failure mode, and (c) Rigid action [4]. 
1- Flexural failure mode: it occurs in CSWs with slender coupling beams which have a small number of main bars. The flexural cracks are formed in the wall subjected to tension and with the increase of stresses, the cracks increase till they move to the coupling beams and with the widening of these cracks a collapse occurs as shown in Fig. 2a.

2- Shear failure mode: it occurs in CSWs with coupling beams that are deep and moderately reinforced. The two modes of shear failure are shear tension and shear sliding as shown in Fig. 2b. For shear tension mode failure, flexural cracks are formed on the tension wall with diagonal cracks on the coupling beams. Shear cracks occur at beam-wall joints and expand till a sliding shear failure occurs for shear sliding mode failure, especially for deep coupling beams.

3- Rigid action: the coupling beams are partially damaged or not damaged with crushing of the highly stressed compression corner. This behavior occurs due to the stiffer connection of the walls by coupling. The coupling beams are much stiffer than the walls. The coupling beams were partially damaged and lots of cracks occur in the tension wall, as shown in Fig. 2c.

\section{Previous research concerning reinforced concrete coupling beams}

Subedi et al. [7] investigated the analysis of reinforced concrete (RC) coupled shear walls with one or two sets of openings even if symmetrical or asymmetrical walls. It was required to carry two stages of analysis, the coupling beams and the complete wall analysis. An experimental test was carried for four models of coupled shear walls to predict the failure mode and ultimate strength of the structure. This study is an extension of a previous study [8]. As it was indicated there are three failure modes for coupled shear walls structure, they depend on the behavior of the coupling beam and the degree of interaction. From this research, it was concluded that shear failure mode is the common mode for coupled shear walls under lateral loads where the walls failed at the highly stressed compression corners by crushing of concrete and the diagonal shear splitting of coupling beams. Harries et al. [9] investigated the behavior, the design and the types of coupling beams according to previous studies. For
RC coupling beams, the type of reinforcement for the coupling beams, whether conventional or diagonal, is determined according to its span to depth ratio and nominal shear stress. It would have been to use reduced section properties and take the loss of stiffness into account to determine an adequate value for the theoretical degree of coupling. They concluded that if the coupling beams span to depth ratio (L/D) is more than or equal to 4 and the shear stress $(\mathrm{Vu})$ is less than or equal to $0.33 \sqrt{f c}$ bd, then the coupling beams will be designed as a standard beam and the mode of failure will be flexural mode. On the other hand if (L/D) is less than 4 and $(\mathrm{Vu})$ is more than $0.33 \sqrt{f c}$ bd, then two intersecting groups of diagonal bars will be used for coupling beams and the mode of failure will be a shear failure. Doran [10] investigated the stiffness of tie members of coupled shear walls (CSWs). A statistical study was presented in addition to the finite element analysis of the coupled shear walls to find the plastic and elastic equivalent stiffness modification parameters of tie members. Lu and Chen [11] investigated a nonlinear micro analysis to investigate the coupled shear walls behavior. For wall modeling the interaction between flexure, shear and axial forces and the shifting of the neutral axis within the wall section were taken into consideration. For coupling beam modeling the interface bond-slip action and the deformation of shear and flexure were considered. The results were compared with the results of the experimental test, which had three specimens of five-story coupled shear walls. It was concluded that there was good agreement between analysis and experimental test, the obtained results approved the effectiveness of the model that have used for coupled shear walls analysis. Wallace [12] performed a study to analyze the results of experiments tests and numerical models for coupled shear walls and coupling beams. For coupling beams, it was found that according to the experimental tests, the diagonal confinement is as effective as the full section confinement according to the ACI 318-08 [3]. According to ACI 318-05 [13], for RC slab, the coupling beam shear strength increased to $15-20 \%$. For post-tension slabs, it also increased by $10 \%$. The coupling beam with diagonal reinforcement has more energy dissipation and total rotation capacity than conventionally reinforced beam. Two models were employed; the first model was based on a rotational spring, while the other model used a nonlinear shear displacement spring. The model with rotational spring (Mn hinge) at the ends of the coupling beam exhibited better matching with the test results than the model with nonlinear shear displacement spring (Vn hinge) at beam-mid span to account shear and shear displacement. Naish 
et al. [14] investigated a numerical model for coupling beam with conventional reinforcement to determine its rotation capacity and moment capacity. The results were compared with various codes. It was concluded that the coupling beam behavior would be controlled by shear and its span to depth ratio should be less than 1.5. For conventional reinforcement, the rotational limit at collapse prevention level should be in the range of 0.01 to 0.02 . The Chinese code for design of concrete structures [2] recommends evolving an alternative design philosophy in the Indian contest for the behavior of post-yield for coupling beams as it is not economical to design structure for its linear behavior during earthquakes so the performance-based seismic design (PBSD) should be considered. The study provided a design technique for RC coupled shear walls. It was investigated that the behavior of coupling beams should be governed by shear, pinned base condition for shear wall offers better nonlinear behavior than fixed base condition. Lande and Ankalkote [15] performed a comparison through seismic analysis between four different models which are; normal RC structure with columns, RC structure with opening in shear walls, RC structure with four sides shear walls and RC structure with coupled shear walls. From the results, it was indicated that coupled shear walls performance is better for resisting lateral loads in high-rise buildings.

\section{Test set up for experimental work}

To experimentally study the behaviour of coupled shear walls, the researchers often consider a section at one-third of the height of the structure. The specimen consists of a section of the coupled shear walls containing the critical coupling beam connecting the two walls. The section is installed in the laboratory so that conditions are provided to suit the deformed shape of the section, which resulted from exposure of the structure to the lateral loads. Four actuators and a rigid L-shaped steel frame were used to test coupling beams specimens that were vertically oriented. Two horizontal actuators installed on the strong wall were used to provide the lateral load [16]-[19]. The setup depended on using a loading beam connecting the two walls to apply lateral loads near the top of the walls to generate double curvature bending in the coupling beams [20] and [21]. Pin assemblies were used to allow free rotation at the base of the walls. An actuator, which was centered on the top-loading beam, was used to provide loads on the specimens as shown in Fig. 3a. In the study carried out by Sesli and Husem [21], one wall segment was firmed to the floor by steel bars and the other wall segment was free. The applied load was transferred by a steel plate that was fixed to the free segment using a displacement control hydraulic jack. The point of inflection was the middle of the coupling beam as the applied load passed through the middle of the specimen. The conditions of real coupling beams are the same as these conditions as shown in Fig. 3 b.

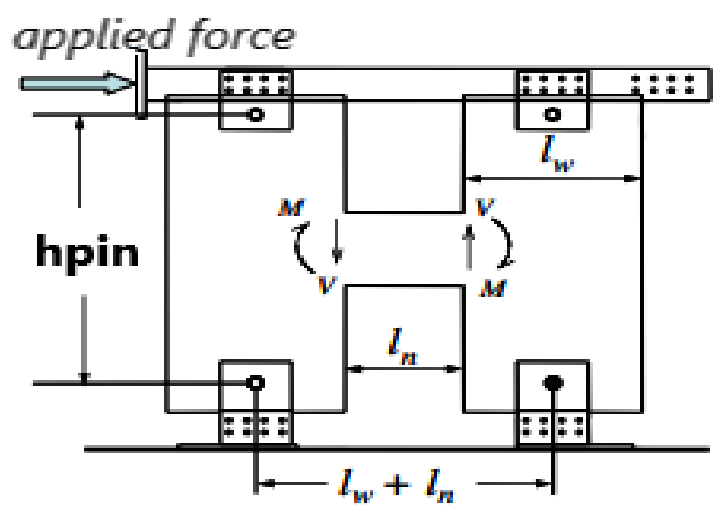

(a)

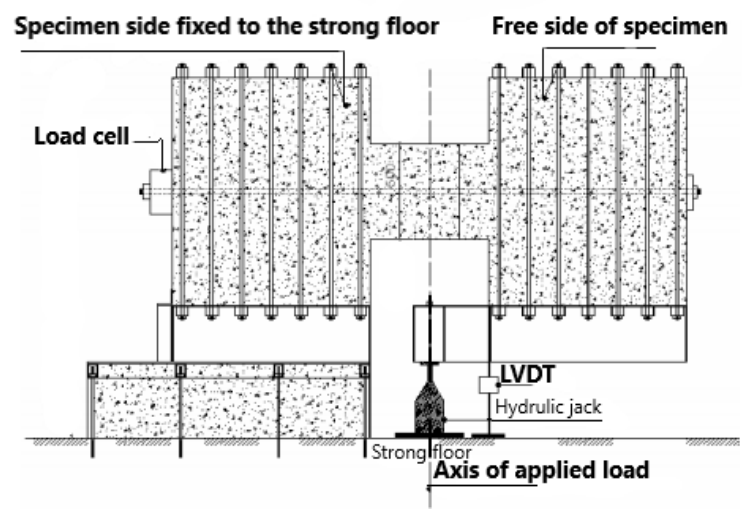

(b)

Fig. 3. Specimen's set up, (a) [21] and (b) [22].

\section{Upgrading and retrofitting of coupled shear walls}

The strengthening had a great effect in improving the behavior of the coupling beams in terms of energy absorption capacity, ductility and increasing the ability to resist lateral loads especially earthquakes. Among several strengthening techniques available in the literature, two main popular ones were discussed here.

\subsection{Coupled shear walls strengthening using bolted steel plates}

Several studies have been carried out concerning the strengthening of coupled shear walls 
using bolted steel plates. Su and Zhu [23] developed a numerical nonlinear finite element model and an experimental study for three full-scale RC coupling beams, two of them were strengthened by external bolted steel plates for proposing different configurations and reinforcement details for strengthened coupling beams. It was concluded that the energy dissipation, deformation and strength are highly improved by bolted steel plates strengthening. In another study, Zhu and Su [24] investigated the behavior of strengthened reinforced concrete coupling beams with bolted steel plates. The method of mixed analysis proposed by Oehlers and Sved [25] to model steel plate strengthened coupling beams was studied to predict the load-carrying capacity of strengthened coupling beams. The rigid plastic analysis technique was used to get the composite effect of the bolt group connections. The results were compared with experimental test results, it was concluded that the strength predicted by the mixed analysis method exhibited good agreement with experimental test results comparing to the rigid plastic model with errors of less than $7 \%$.

\subsection{Coupled shear walls strengthening using FRP laminates}

There is always a search for new materials in order to be used to extend the existing structures service life in addition to the design and construction of new structures that are capable of resisting external loads, especially seismic loads. Fibrereinforced polymers are considered one of these materials, which are characterized by their lightweight, high strength and non-corrosiveness. FRP materials have been widely used in new construction and rehabilitation of structures, where they are used for strengthening to improve the seismic behavior of structures. Composites of FRP used to reinforce frame molds and bridge decks. There are many studies, especially in the last decade to strength and repair structures by FRP materials because of its importance in enhancing the behavior of the structural element. Asfa et al. [26] studied the effect of FRP strengthening on the behavior of shear walls with openings using FRP strips around the openings. FE analysis was investigated and the results were verified with an experimental study, it was concluded that all different techniques of strengthening increased the ductility and strength of the walls. Alferjani et al. [27] investigated the importance of using carbon fiber reinforced polymer (CFRP) sheets for RC beams shear strengthening. It was investigated that using CFRP sheets extended the service life of reinforced concrete structures and provided an economical solution. Shaheen et al. [28] investigated a numerical model to study the effect of intermediate crack (IC) deponding of shear walls which externally bonded by FRP sheets. The nonlinear response of strengthened shear walls was predicted and the results were compared with an experimental study. It was concluded that maximum load capacity and nonlinear hysteretic response of walls were affected by IC deponding mechanism but it doesn't have an important effect for predicting the initial stiffness. Chen and Teng [29] developed a new strengthening model and compared it with experimental data to present a new design suggestion for investigating the capacity of shear of FRP Strengthened RC beams. It was concluded that Uwrapping of GFRP bonded on the RC deep beam enhances the shear strength up to $16 \%$ and the bottom layer of CFRP fabric bonded on the tension face of beams enhances the shear strength up to $10 \%$. Shen et al. [30] studied the effect of using basalt fiber reinforced polymer for repairing corroded RC shear walls in seismic regions. An experimental study was investigated for seven walls with an aspect ratio of 1.6, three of them were repaired with externally bonded BFRP jackets. An analytical study for two models was proposed also. From the results, it was illustrated that the bond behavior between concrete and reinforcement is improved by using BFRP jackets and the calculated results from theoretical models have good agreement with test results. Experimental investigation on the strengthening of coupled shear walls using FRP materials has been conducted by many researchers. Meftah and Tounsi [31] studied the behavior of externally CFRP sheets strengthening of damaged coupled shear walls structures by using mixed finite element method for free vibration analysis, They also studied the effects of damage extent and vibration characteristics. It was concluded that the damage had a worthy effect on the vibration characteristics and the bending of reinforced concrete shear walls with openings. In the study carried out by Riyazi et al. [22], it was observed that strengthening the coupling beam using external CFRP sheets could improve its performance. They also studied the effect of slab diaphragm on constraining coupling beams. Results showed that the longitudinal constraint may influence the ductility and strength of the coupling beams. Four longitudinally constrained coupling beams were tested and two of these specimens were strengthened by CFRP sheets and retested. They found that the longitudinal constraint may not be effective for the coupling beams strength with conventional reinforcement and that effect may be significant in coupling beams with diagonal reinforcement. Li et al. 
[18] tested four FRP laminates strengthened specimens of coupling beams under cyclic loading. Different schemes of carbon fibre reinforced polymer laminates (CFRP) strengthening techniques were used. From the results, it was investigated that the ductility and energy absorption capacity were improved. . Some examples of steel plates and FRP sheets strengthening techniques are shown in Fig. 4 and Fig. 5 respectively.
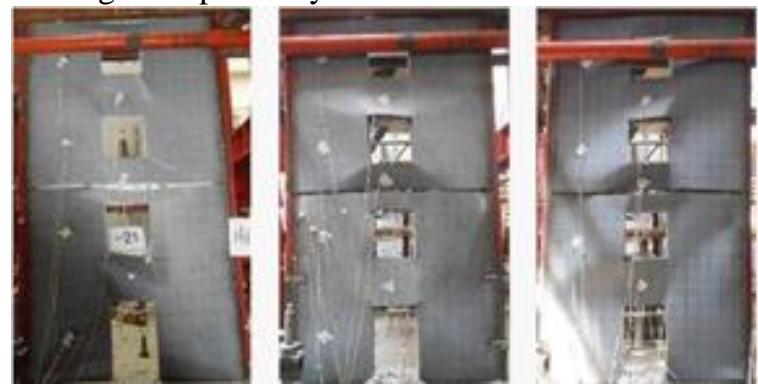

Fig. 4. An example of Strengthening coupled shear walls by external steel plates [32].

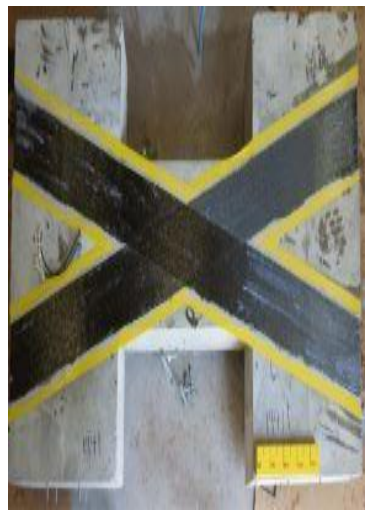

(a)

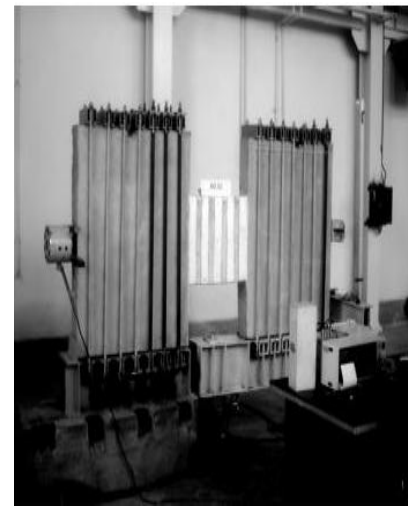

(b)
Fig. 5. Strengthening coupled shear walls by FRP sheets, (a) External CFRP diagonal sheets and [33]. (b) VL sheets [22].

\section{Modeling of coupled shear walls strengthened by FRP materials}

It was very important to conduct numerical studies for non-linear analysis on high-rise building models to measure the efficiency of FRP laminates strengthening in resisting earthquakes, increasing the ductility and the energy absorption capacity of the structure. A number of studies have been investigated. Meftah et al. [34] studied mixed finite element method for strengthening RC coupled shear walls structures by thin composites plates having variable fibers spacing. Three models were used for coupled shear walls having 15, 20 and 30 stories level under three different earthquakes to investigate the influence of coupled shear walls geometric characteristics under seismic loads. Results showed that the seismic response of strengthened CSW with variable spacing is the same to that with uniform spacing. Moreover, significant improvements in the seismic deflection were observed when the fibres were gathered near the wall edges. Kheyroddin [35] investigated two methods of strengthening for improving the behavior of RC coupling beams. Three groups of RC coupling beams were analyzed through numerical analysis; the first one was strengthened by externally bonded steel plates and the other two strengthened with FRP sheets. The externally bonded FRP sheets and FRP sheets wrapping techniques for strengthening coupling beams were used. In this study, they focused on generating a model that can predict the general behavior of strengthened coupling beams. They investigated the strengthening methods including the use of steel plates and FRP sheets. They found through comparing the shear force- chord rotation behavior of specimens and control model that ultimate load and chord rotation capacity had been upgraded for all specimens. Meftah et al. [36] studied the dynamic behavior of strengthened RC coupling beams with CFRP composite plates attached on their sides, three layered sandwich coupling beams and wall elements were studied by finite element formulation. Elcentro and Northridge earthquake records were employed in this study. It was concluded that dominant range frequencies of earthquake records and the geometrical characteristics of shear wall control the mitigation of seismic behavior of strengthened CFRP composite plates coupled shear walls. Hakimi and Madandoust [37] studied numerically the behavior of reinforced concrete (RC) coupling beams strengthened with carbon fibre-reinforced polymer (CFRP) and glass fiber reinforced polymer (GFRP) sheets. The externally bonded reinforcement method (EBR) and near-surface mounted method (NSM) were analyzed. It was concluded that the ductility and shear strength were increased by using FRP composites and the EBR method was more effective to increase the strength and ductility. Honarparast and Chaallal [38] carried out a nonlinear time history analysis of two 20 -storeis coupled shear walls located in western seismic Canadian zone and CFRP retrofitted coupled shear wall. One of the two models was designed according to National Building Code of Canada (NBCC 1941) (old code) [39] and the other one was designed with modern code (NBCC 2015) [40] by comparing the results of three methods, it was concluded that CFRP retrofit is efficient as the interstory drift was decreased to values close to modern code and the design shear which determined by modern code was adequate. 


\section{Conclusions}

The following conclusions can be drawn, based on the previous literature:

- Coupling Beams are important structural elements that link the shear walls and increase their ability to resist earthquakes.

- Diagonal reinforcement of the coupling beams is preferred due to its effectiveness in increasing the earthquake resistance of the coupled shear walls, but its difficulty in implementation and the presence of some already established buildings led to the search for alternatives to it through strengthening.

- The techniques of strengthening for the coupling beams are variable, and these techniques were studied whether experimentally or analytically, and many studies were investigated. Indeed, the strengthening had a great effect in improving the behavior of the coupling beams in terms of energy absorption capacity or ductility and increasing the ability to resist lateral loads, especially earthquakes.

- Strengthening the coupled shear wall section with FRP materials resulted in a noticeable enhancement in its overall seismic behavior.

- Strengthening of coupled shear walls with CFRP exhibited a greater and more effective influence than other FRP materials in terms of load-carrying capacity and energy dissipation capacity.

- The full wrapping FRP sheets strengthening technique and strengthening with FRP sheets above and below coupling beam technique showed very high efficiency even from diagonal reinforcement and the whole model diagonal FRP sheets strengthening technique, especially in the case of CFRP sheets strengthening.

- The diagonal FRP sheets strengthening on the coupling beam only exhibited almost the same results as the total diagonal strengthening. Therefore, we recommend an experimental study under cycling loading to confirm this matter for its possible application in reality and to support the already constructed buildings.

\section{References}

[1] J. Bezelga, "Coupling beams of structural walls - Modelling techniques for the seismic evaluation of RC systems," vol. 2015, no. July, 2015.

[2] GB 50010-2010, "Code for design of concrete structures Beijing," China Archit. Press, vol. 2013, 2010.

[3] A. C. I. ACI, Building Code Requirements for Structural Concrete. 2014.

[4] S. Honarparast, "Nonlinear Behaviour of Coupled Shear Walls Strengthened With Externally Bonded Carbon Fibre Reinforced Polymer Composite Under Seismic Loadings," pp. 1-223, 2018.

[5] NRCC, "National Building Code of Canada," vol. 1, p. 1222, 2010.

[6] S. Zheng, Q. Xu, and Z. Li, "Failure-mode Based Coupled Shear Wall Optimization Design," vol. 169, pp. 29-32, 2012, doi: 10.4028/www.scientific.net/AMM.166-169.29.

[7] N. K. Subedi, A. K. Marsono, and G. Aguda, "Analysis of reinforced concrete coupled shear wall structures," Struct. Des. Tall Build., vol. 8, no. 2, pp. 117-143, 1999, doi: 10.1002/(SICI)1099-1794(199906)8:2<117::AIDTAL124>3.0.CO;2-7.

[8] N. K. Subedi, "R C - C O U P L E D SHEAR W A L L STRUCTURES. I: ANALYSIS O F COUPLING BEAMS By Nutan Kumar Subedi, 1 Member, ASCE,” J. Struct. Eng, vol. 117 , no. 3, pp. 667-680, 1991.

[9] K.A.Harries, B.Gong, and B.M.SHahrooz, "Behavior and design of reinforced concrete, steel and steel-concrete coupling beams," Earthquake Spectra, vol. 16, no. 4, 2000.

[10] B. Doran, "Elastic-plastic analysis of R/C coupled shear walls: The equivalent stiffness ratio of the tie elements," J. Indian Inst. Sci., vol. 83, no. 3-4, pp. 87-94, 2003.

[11] X. Lu and Y. Chen, "Modeling of Coupled Shear Walls and Its Experimental Verification,” J. Struct. Eng., vol. 131, no. 1, pp. 75-84, 2005, doi: 10.1061/(asce)07339445(2005)131:1(75).

[12] J. W. Wallace, "Behavior, design, and modeling of structural walls and coupling beams - Lessons from recent laboratory tests and earthquakes," Int. J. Concr. Struct. Mater., vol. 6, no. 1, pp. 3-18, 2012, doi: 10.1007/s40069-012-0001-4.

[13] J. K. Wight et al., “ACI Committee 318,"BUILDING CODE REQUIREMENTS FOR STRUCTURAL CONCRETE (ACI 318-05) AND COMMENTARY (ACI 318R-05)"," Am. Concr. Institute, Farmingt. Hills, MI, vol. 2003, p. 430, 2005.

[14] D. Naish, A. Fry, R. Klemencic, and J. Wallace, "Reinforced Concrete Coupling Beams - Part I : Testing," ACI Struct. J., vol. 110, no. 6, pp. 1057-1067, 2013.

[15] P. P. S. Lande and V. S. Ankalkote, "Evaluation of Coupled Shear wall in High-Rise Building," pp. 2416-2420, 2018.

[16] E. Lim, S. Hwang, C. Cheng, and P. Lin, "Cyclic Tests of Reinforced Concrete Coupling Beam with Intermediate SpanDepth Ratio," no. 113, pp. 515-524, 2016, doi: $10.14359 / 51688473$.

[17] A. K. H. Kwan and Z. Z. Zhao, "Testing of coupling beams with equal end rotations maintained and local joint deformation allowed," no. 1, 2002.

[18] X. Li, L. Liu, H. L. Lv, and S. Y. Sha, "Seismic retrofit of short RC coupling beams using CFRP composites," Mag. Concr. Res., vol. 68, no. 5, pp. 260-270, 2016, doi: 10.1680/jmacr.15.00057.

[19] X. Li, Y. S. Sun, B. D. Ding, and C. Z. Xia, "Cyclic Behavior of Deep RC Coupling Beams with Different Reinforcement Layouts,” J. Earthq. Eng., vol. 24, no. 1, pp. 155-174, 2020, doi: 10.1080/13632469.2018.1452806.

[20] S. F. Breña, M. Asce, and O. Ihtiyar, "Performance of Conventionally Reinforced Coupling Beams Subjected to Cyclic Loading," no. June, pp. 665-676, 2011, doi: 10.1061/(ASCE)ST.1943-541X.0000316. 
[21] H. Sesli and M. Husem, "Experimental Investigation on Cyclic Behavior of Reinforced Concrete Coupling Beams Under Quasi-static Loading," Int. J. Civ. Eng., vol. 19, no. 4, pp. 381-400, 2021, doi: 10.1007/s40999-020-00573-w.

[22] M. Riyazi, M. R. Esfahani, and H. Mohammadi, "Behavior of coupling beams strengthened with Carbon Fiber Reinforced Polymer sheets,” Int. J. Eng. Trans. B Appl., vol. 20, no. 1, pp. 49-58, 2007.

[23] R. K. L. Su and Y. Zhu, "Experimental and numerical studies of external steel plate strengthened reinforced concrete coupling beams," Eng. Struct., vol. 27, no. 10, pp. 15371550, 2005, doi: 10.1016/j.engstruct.2005.04.012.

[24] Y. Zhu and R. K. L. Su, "Behavior of strengthened reinforced concrete coupling beams by bolted steel plates, Part 2: Evaluation of theoretical strength," Struct. Eng. Mech., vol. 34, no. 5, pp. 563-580, 2010, doi: 10.12989/sem.2010.34.5.563.

[25] D. J. Oehlers and G. Sved, "Composite Beams with LimitedSlip-Capacity Shear Connectors," J. Struct. Eng., vol. 121, no. 6, pp. 932-938, 1995, doi: 10.1061/(asce)07339445(1995)121:6(932).

[26] M. Asfa, D. Mostofinejad, and N. Abdoli, "Effect of FRP strengthening on the behavior of shear walls with opening," Adv. FRP Compos. Civ. Eng. - Proc. 5th Int. Conf. FRP Compos. Civ. Eng. CICE 2010, pp. 837-840, 2011, doi: 10.1007/978-3-642-17487-2_184.

[27] M. B. S. Alferjani, "Shear Strengthening of Reinforced Concrete Beams Using Carbon Fiber Reinforced Polymer Laminate: A Review," Am. J. Civ. Eng., vol. 2, no. 1, p. 1, 2014, doi: 10.11648/j.ajce.20140201.11.

[28] I. K. Shaheen, C. A. Cruz-Noguez, and D. T. Lau, "Seismic retrofit of R.C. shear walls with externally bonded FRP towsheets," Proceedings, Annu. Conf. - Can. Soc. Civ. Eng., vol. 2, no. January, pp. 1417-1426, 2013.

[29] J. F. Chen and J. G. Teng, "Shear capacity of FRPstrengthened RC beams: FRP debonding," Constr. Build. Mater., vol. 17, no. 1, pp. 27-41, 2003, doi: 10.1016/S09500618(02)00091-0.

[30] D. Shen, Q. Yang, C. Huang, Z. Cui, and J. Zhang, "Tests on seismic performance of corroded reinforced concrete shear walls repaired with basalt fiber-reinforced polymers," Constr. Build. Mater., vol. 209, pp. 508-521, 2019, doi: 10.1016/j.conbuildmat.2019.02.109.

[31] S. A. Meftah and A. Tounsi, "Lateral stiffness and vibration characteristics of damaged RC coupled shear walls strengthened with thin composite plates," Build. Environ., vol. 42, no. 10, pp. 3596-3605, 2007, doi: 10.1016/j.buildenv.2006.10.049.

[32] H. Liu, W. Cao, H. Dong, and J. Zhang, "Experiment on seismic behavior of composite shear wall with concealed partitioned steel plates," Tianjin Daxue Xuebao (Ziran Kexue yu Gongcheng Jishu Ban)/Journal Tianjin Univ. Sci. Technol., vol. 49, no. 9, pp. 944-950, 2016, doi: $10.11784 /$ tdxbz201508046.

[33] S. Honarparast, G. El-Saikaly, and O. Chaallal, "Externally bonded carbon fiber-reinforced polymer composites for seismic retrofit of reinforced concrete coupling beams designed according to old codes," Adv. Struct. Eng., vol. 22, no. $6, \quad$ pp. 1412-1425, 2019, doi: $10.1177 / 1369433218815609$.

[34] S. A. Meftah, R. Yeghnem, A. Tounsi, and E. A. Adda bedia, "Seismic behavior of RC coupled shear walls repaired with CFRP laminates having variable fibers spacing," Constr. Build. Mater., vol. 21, no. 8, pp. 1661-1671, 2007, doi: 10.1016/j.conbuildmat.2006.05.011.

[35] A. Kheyroddin, H. Naderpour, G. Ghodrati Amiri, and S. R. Hoseini Vaez, "Influence of carbon fiber reinforced polymers on upgrading shear behavior of RC coupling beams," Iran. J.
Sci. Technol. Trans. B Eng., vol. 35, no. C2, pp. 155-169, 2011.

[36] S. A. Meftah, F. Mohri, and E. M. Daya, "Seismic behavior of RC coupled shear walls with strengthened coupling beams by bonded thin composite plates," KSCE J. Civ. Eng., vol. 17, no. 2, pp. 403-414, 2013, doi: 10.1007/s12205-013-12869.

[37] S. Hakimi and R. Madandoust, "Numerical Study on Coupling Beam Retrofitted Using CFRP and GFRP Sheets," Am. J. Eng. Appl. Sci., vol. 11, no. 3, pp. 1125-1129, 2018, doi: 10.3844/ajeassp.2018.1125.1129.

[38] S. Honarparast and O. Chaallal, "Seismic Performance of Coupled Shear Walls Designed according to Old and New Codes and Retrofitted with Eb-CFRP Composites," J. Earthq. Eng., vol. 00, no. 00, pp. 1-24, 2020, doi: 10.1080/13632469.2020.1743387.

[39] National Research Council of Canada and Canadian Commission on Building and Fire Codes, "National Building Code of Canada 1941," no. 1068.

[40] National Research Council of Canada and Canadian Commission on Building and Fire Codes, "National Building Code of Canada 2015," vol. 1, p. 708, 2015.

\section{List of symbols}

L/D: Span to depth ratio of coupling beam

Vu: Shear stress

b*d: Cross section

$f c^{\prime}$ : Compressive strength

FRP: Fibre reinforced polymers

CB: coupling beam

CSWs: Coupled shear walls

CFRP: Carbon Fibre Reinforced Polymer

GFRP: Glass Fibre Reinforced Polymer

BFRP: Basalt Fibre Reinforced Polymer 